\title{
Evaluation of the anti-inflammatory, anti-catabolic and pro-anabolic effects of E-caryophyllene, myrcene and limonene in a cell model of osteoarthritis
}

\author{
Ana Teresa Rufino ${ }^{\mathrm{a}, \mathrm{b}}$, Madalena Ribeiro ${ }^{\mathrm{a}, \mathrm{b}}$, Cátia Sousa ${ }^{\mathrm{a}, \mathrm{b}}$, Fernando Judas ${ }^{\mathrm{c}, \mathrm{d}}$, \\ Lígia Salgueiro $^{\mathrm{a}, \mathrm{e}}$, Carlos Cavaleiro ${ }^{\mathrm{a}, \mathrm{e}}$, Alexandrina Ferreira Mendes ${ }^{\mathrm{a}, \mathrm{b}, *}$ \\ ${ }^{a}$ Centre for Neuroscience and Cell Biology, University of Coimbra, Coimbra, Portugal \\ ${ }^{\mathrm{b}}$ Faculty of Pharmacy, University of Coimbra, Coimbra, Portugal \\ c Orthopedics Department and Bone Bank, University and Hospital Center of Coimbra, Coimbra, Portugal \\ ${ }^{\mathrm{d}}$ Faculty of Medicine, University of Coimbra, Coimbra, Portugal \\ e Centro de Estudos Farmacêticos, Faculty of Pharmacy, University of Coimbra, Coimbra, Portugal
}

\section{A R T I C L E I N F O}

\section{Article history:}

Received 23 October 2014

Received in revised form

14 January 2015

Accepted 16 January 2015

Available online 23 January 2015

Keywords:

Osteoarthritis

Chronic inflammation

NF- $\kappa B$

MAPK

Natural products

\begin{abstract}
A B S T R A C T
Osteoarthritis is a progressive joint disease and a major cause of disability for which no curative therapies are yet available. To identify compounds with potential anti-osteoarthritic properties, in this study, we screened one sesquiterpene, E-caryophyllene, and two monoterpenes, myrcene and limonene, hydrocarbon compounds for anti-inflammatory, anti-catabolic and pro-anabolic activities in human chondrocytes. At non-cytotoxic concentrations, myrcene and limonene inhibited IL-1 $\beta$-induced nitric oxide production $\left(\mathrm{IC}_{50}=37.3 \mu \mathrm{g} / \mathrm{ml}\right.$ and $85.3 \mu \mathrm{g} / \mathrm{ml}$, respectively), but $E$-caryophyllene was inactive. Myrcene, and limonene to a lesser extent, also decreased IL- $1 \beta$-induced NF- $\kappa \mathrm{B}$, JNK and p38 activation and the expression of inflammatory (iNOS) and catabolic (MMP-1 and MMP-13) genes, while increasing the expression of anti-catabolic genes (TIMP- 1 and -3 by myrcene and TIMP- 1 by limonene). Limonene increased ERK $1 / 2$ activation by $30 \%$, while myrcene decreased it by $26 \%$, relative to IL- $1 \beta$-treated cells. None of the compounds tested was able to increase the expression of cartilage matrix-specific genes (collagen II and aggrecan), but both compounds prevented the increased expression of the non-cartilage specific, collagen I, induced by IL-1 $\beta$. These data show that myrcene has significant anti-inflammatory and anti-catabolic effects in human chondrocytes and, thus, its ability to halt or, at least, slow down cartilage destruction and osteoarthritis progression warrants further investigation.
\end{abstract}

(c) 2015 Elsevier B.V. All rights reserved.

\section{Introduction}

Osteoarthritis (OA) is a multifactorial degenerative joint disease characterized by inflammation and progressive loss of the articular cartilage, associated with changes in the subchondral bone and other joint tissues. It affects $10-15 \%$ of the world population and is a major cause of disability, not only in the elderly, as well as in the workforce population (Zhang and Jordan, 2010). Existing therapeutic approaches

\footnotetext{
* Corresponding author at: Center for Neuroscience and Cell Biology, University of Coimbra, Edifício da Faculdade de Medicina, Polo I, $1^{\circ}$ piso, Rua Larga, 3004-504 Coimbra, Portugal. Tel.: +351 239 480209; fax: + 351239488503

E-mail addresses: ana.t.rufino@gmail.com (A.T. Rufino), madalena_ribeiro8@hotmail.com (M. Ribeiro), catota_coura@hotmail.com (C. Sousa), fernandojudas@gmail.com (F. Judas), ligia@ff.uc.pt (L. Salgueiro), Cavaleir@ff.uc.pt (C. Cavaleiro), afmendes@ff.uc.pt (A.F. Mendes).
}

are mainly symptomatic, thus novel drugs with disease-modifying and chondroprotective properties, the so-called disease-modifying osteoarthritis drugs, are required to halt disease progression and decrease its huge socio-economic impact (Goldring and Goldring, 2007; Kaplan et al., 2013).

Plant-derived compounds show important biological properties that can be explored in the context of OA for identification of compounds with potential anti-osteoarthritic activity (Calixto et al., 2004; Khalife and Zafarullah, 2011). Among compounds of plant origin, those found in essential oils present favorable pharmacokinetic properties, namely lipophilicity and low molecular weight (Miguel, 2010). Our previous studies have been focused in identifying essential oils with antiinflammatory and anti-catabolic properties in human chondrocytes to be used as sources of compounds with potential anti-osteoarthritic activity (Neves et al., 2009; Rufino et al., 2014a). In this context, we recently identified the essential oils of Eryngium duriaei subsp. juresianum and Lavandula luisieri as possessing anti-inflammatory properties 
in human chondrocytes (Rufino et al., 2014a). The current study aims at identifying active compounds of these essential oils and further characterizing their pharmacological properties in human chondrocytes.

For this, mechanisms relevant as pharmacological targets for the development of anti-osteoarthritic drugs need to be addressed. Although OA etiology is not yet completely understood, proinflammatory cytokines, like interleukin- $1 \beta$ (IL-1 $\beta$ ), play a central role in disease development and progression by inducing the expression of cartilage matrix-degrading enzymes and impairing anabolic and anti-catabolic responses in chondrocytes (Goldring et al., 2008). The consequent upregulated degradative process, together with impaired reparative responses, results in progressive cartilage loss, the hallmark of OA.

Matrix metalloproteases (MMPs) and aggrecanases are the main enzymes responsible for hydrolyzing the major articular cartilagespecific matrix components, collagen II and aggrecan. This is accompanied by impaired reparative responses involving downregulation of the natural MMP inhibitors, the tissue inhibitor of metalloproteases (TIMP) family, decreased synthesis of collagen II and aggrecan and increased expression of non-articular cartilage matrix components, like collagen I (Troeberg and Nagase, 2012). Moreover, increased production of pro-inflammatory and pro-catabolic mediators, like nitric oxide (NO), amplifies and perpetuates cartilage destruction (Boileau et al., 2002; Rosa et al., 2008; Sasaki et al., 1998). The transcription factor, Nuclear Factor- $\kappa \mathrm{B}(\mathrm{NF}-\kappa \mathrm{B})$, and the family of mitogen-activated protein kinases (MAPK) play a central role in modulating the expression of those catabolic and inflammatory mediators (Goldring and Otero, 2011) and, thus, agents that suppress their activity have the potential to effectively decrease cartilage destruction and, therefore, OA progression (Berenbaum, 2004). Furthermore, compounds that can also restore anabolic and anti-catabolic gene expression have the potential to promote cartilage repair.

Therefore, we used primary human chondrocyte cultures stimulated with IL-1 $\beta$ as an in vitro cartilage degradation model that emulates the damage seen in OA. Using this model, we evaluated the inhibition of IL- $1 \beta$-induced NO production as a simple screening assay. The essential oils of $E$. duriaei subsp. juresianum and $L$. luisieri were separated into several fractions that were then screened using the assay mentioned above. The chemical composition of the fractions tested was elucidated and compounds present in the active fractions and commercially available were selected for screening using the same assay. The compounds selected were obtained with a high degree of purity from commercial sources and those found to be capable of inhibiting IL-1 $\beta$-induced NO production were selected for further assessment of anti-osteoarthritic potential. For this, we evaluated their ability to modulate IL-1 $\beta$-induced signaling pathways involved in the expression of inflammatory and catabolic genes, namely activation of NF- $\kappa \mathrm{B}$ and the MAPK family members, Jun terminal Kinase (JNK), p38 and Extracellular signal-Regulated Kinase 1/2 (ERK1/2). Then, we evaluated the ability of those compounds to counteract the effects of IL- $1 \beta$ on the expression of inflammatory (iNOS), catabolic (MMP-1 and -13), anti-catabolic (TIMP-1 and -3) and extracellular matrix (collagen I, collagen II and aggrecan) genes in human articular chondrocytes.

\section{Material and methods}

\subsection{Essential oil fractionation and chemical analysis}

The essential oils of E. duriaei subsp. juresianum and L. luisieri were fractionated by flash chromatography on silica gel 63$200 \mu \mathrm{m}$ (Merck) using a $2 \mathrm{~cm} \times 40 \mathrm{~cm}$ Omnifit (Sigma-Aldrich) glass columns. Elution was made in step gradients from $100 \%$ of $n$-pentane, $n$-pentane /ethyl ether mixtures, till a final concentration of $100 \%$ ethyl ether. Collected fractions were analyzed by gas chromatography-mass spectroscopy (GC/MS) and combined if having similar composition. Analysis was performed using a Hewlett-Packard 6890 gas chromatograph fitted with a HP1 fused silica column (polydimethylsiloxane $30 \mathrm{~m} \times 0.25 \mathrm{~mm}$ i.d., film thickness $0.25 \mu \mathrm{m}$ ), interfaced with an Hewlett-Packard mass selective detector 5973 (Agilent Technologies) operated by HP Enhanced ChemStation software, version A.03.00. GC-MS parameters: oven temperature program: $70-220{ }^{\circ} \mathrm{C}\left(3{ }^{\circ} \mathrm{C} \mathrm{min}-1\right)$, $220{ }^{\circ} \mathrm{C}(15 \mathrm{~min})$; injector temperature: $250{ }^{\circ} \mathrm{C}$; carrier gas: helium, adjusted to a linear velocity of $30 \mathrm{~cm} \mathrm{~s}^{-1}$; splitting ratio 1:40; interface temperature: $250{ }^{\circ} \mathrm{C}$; MS source temperature: $230{ }^{\circ} \mathrm{C}$; MS quadrupole temperature: $150{ }^{\circ} \mathrm{C}$; ionization energy: $70 \mathrm{eV}$; ionization current: $60 \mu \mathrm{A}$; scan range: 35-350 units; scans s ${ }^{-1}: 4.51$. Compounds were identified through their GC retention and mass spectra. Retention indices, calculated by linear interpolation relative to retention times of $\mathrm{C}_{8}-\mathrm{C}_{23}$ of $n$-alkanes, were compared with those of authentic products included in laboratory database (CEF/Faculty of Pharmacy, University of Coimbra) and/or the literature data. Acquired mass spectra were compared with reference spectra from the laboratory database, Wiley/NIST library (McLafferty, 2009) and literature data (Adams, 1995; Cavaleiro et al., 2011; Joulain, 1998; Videira et al., 2013). Relative amounts of individual components were calculated based on the total ion chromatogram peak areas.

\subsection{Cartilage samples and chondrocyte isolation}

Human chondrocytes were isolated by enzymatic digestion (Rosa et al., 2008) of knee cartilage from the distal femoral condyles of multi-organ donors $(20-70$ years old, mean $=52.9$, $n=31$ ) and patients (58-73 years old, mean $=65, n=5$ ) undergoing total knee arthroplasty at the Orthopaedic Department and Bone Bank of the University and Hospital Center of Coimbra (CHUC). The cartilage samples presented variable degrees of degradation, ranging from intact to severely damaged. All procedures were approved by the Ethics Committee of CHUC (protocol approval numbers 8654/DC and HUC-13-05).

\subsection{Cell cultures and treatments}

Primary non-proliferating chondrocyte cultures were established from non-pooled cartilage samples. The human chondrocytic cell line, C28/I2, kindly provided by Prof. Mary Goldring (currently at the Hospital for Special Surgery, New York) and

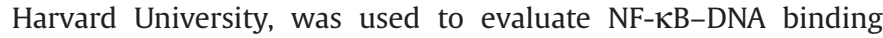
activity. The cell cultures were serum-starved for at least $8 \mathrm{~h}$ and maintained thereafter in serum-free culture medium. The test compounds, diluted in DMSO (Sigma-Aldrich, St Louis, MO, USA) to achieve the concentrations indicated in figures and their legends, were added to the chondrocyte cultures $30 \mathrm{~min}$ before the pro-inflammatory stimulus (IL- $1 \beta, 10 \mathrm{ng} / \mathrm{ml}$ ) and maintained for the experimental period indicated in figure legends. The final concentration of DMSO did not exceed $0.1 \%(\mathrm{v} / \mathrm{v})$. E-caryophyllene (purity $>98.5 \%$ ) and myrcene (purity $\geq 95.0 \%$ ) were from SigmaAldrich (St Louis, MO, USA) and limonene (purity 90\%) was from Fluka.

\subsection{Nitric oxide production}

Nitric oxide production was evaluated as the amount of nitrite accumulated in primary chondrocyte culture supernatants after $24 \mathrm{~h}$ treatment with IL-1 $\beta$, following pre-treatment with noncytotoxic concentrations of the fractions of the essential oils or the test compounds. Nitrite concentration was measured using the 
spectrophotometric method based on the Griess reaction (Green et al., 1982).

\subsection{Western blot analysis}

Total and cytoplasmic extracts were prepared as described before (Goldring and Otero, 2011). Proteins were separated by SDS-PAGE under reducing conditions and electrotransferred onto PVDF membranes. These were probed overnight with the following primary antibodies: mouse monoclonal anti-human iNOS (R\&D systems, Minneapolis, MN), mouse polyclonal anti-human

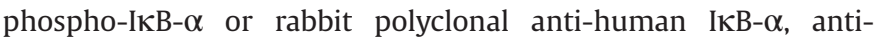
human phospho-JNK, anti-human phospho-p38 or anti-human phospho-ERK1/2 (Cell Signaling Technology, Inc., Danvers, MA) and then with anti-rabbit or anti-mouse alkaline phosphataseconjugated secondary antibodies (GE Healthcare, UK). Mouse antihuman $\beta$-Tubulin monoclonal antibody was used to detect $\beta$-Tubulin as a loading control. Enhanced ChemiFluorescence reagent (GE Healthcare) was used to detect immune complexes. Image analysis was performed with ImageQuant TL software (GE Healthcare). The results presented are the normalized ratio between the intensities of the bands corresponding to the protein of interest and to the protein used as loading control.

\section{6. $N F-\kappa B$ transcription factor assay}

A colorimetric ELISA-based assay (NoShift Transcription Factor Assay Kit, Novagen, La Jolla, CA) was used to evaluate the presence of active NF- $\kappa B$ dimers, capable of binding to the cognate consensus oligonucleotide sequence. For this purpose, nuclear extracts from C-28/I2 cells were incubated with a biotinylated consensus $\mathrm{NF}-\kappa \mathrm{B}$ oligonucleotide (NoShift NF- $\kappa \mathrm{B}$ Reagents; Novagen) and the assay performed according to the manufacturer's instructions. The absorbance intensity in each sample is directly proportional to the amount of NF- $\kappa B-D N A$ complexes formed and, thus, to the amount of active NF- $\kappa \mathrm{B}$ dimers present in each sample. In parallel, the specificity of the reaction was confirmed in competition assays where addition of a 10-fold molar excess of non-biotinylated wildtype or mutant oligonucleotides (NoShift NF- $\kappa B$ Reagents; Novagen) to binding reactions containing nuclear extracts from IL-1 $\beta$ treated cells abrogated or did not affect, respectively, the formation of NF-KB-DNA complexes.

\subsection{Total RNA extraction and quantitative real-time RT-PCR ( $q R T$ - PCR)}

Total RNA was extracted from human condrocytes using TRIzol $^{\circledR}$ Reagent (Invitrogen, Life Technologies, Co; Paisley, UK) and quantified using a NanoDrop ND-1000 spectrophotometer at $260 \mathrm{~nm}$. Purity and integrity of RNA were assessed as the 240/ 260 and 280/260 ratios. The cDNA was reverse-transcribed using the iScript Select cDNA Synthesis Kit (Bio-Rad), beginning with
$1 \mu \mathrm{g}$ of RNA. Specific sets of primers for iNOS, MMP-1, MMP-13, TIMP-1, TIMP-3, collagen II, collagen I, aggrecan and HPRT-1 (Table 1) were designed using Beacon Designer software (Premier Biosoft International, Palo Alto, CA). PCR reactions were performed using $25 \mu \mathrm{g} / \mathrm{ml}$ of transcribed cDNA in a final volume of $20 \mu \mathrm{L}$.

The efficiency of the amplification reaction for each gene was calculated using a standard curve of a series of diluted cDNA samples, and the specificity of the amplification products was assessed by analyzing the melting curve generated in the process.

The results for each gene of interest were normalized against HPRT-1, the housekeeping gene found to be the most stable under the experimental conditions used. Gene expression changes were analyzed using the built-in iQ5 Optical system software v2, which enables the analysis of the results with the Pfaffl method, a variation of the $\Delta \Delta \mathrm{CT}$ method corrected for gene-specific efficiencies (Nolan et al., 2006)

\subsection{Statistical analysis}

Results are presented as mean \pm S. E. M. Each subject contributed only once to the statistical analysis which was performed using GraphPad Prism (version 5.00). The Kolmogorov-Smirnov test was used to assess normality for the observations themselves or for the observed differences. As this test showed that in all experiments the results were normally distributed, the statistical analysis was performed using the paired $t$-test for comparison of each condition with its respective control and one-way ANOVA for comparison of all conditions. Results were considered statistically significant at $P<0.05$.

\section{Results}

\subsection{Selection of inhibitors of IL-1-induced iNOS expression and NO production}

Various fractions of the essential oils of E. duriaei subsp. juresianum and L. luisieri were separated in amounts sufficient for pharmacological screening. The composition of these fractions was fully elucidated and is reported in Table 2.

The fractions obtained were then tested at non-cytotoxic concentrations ranging from 10 to $50 \mu \mathrm{g} / \mathrm{ml}$ (Supplementary data). The results (Fig. 1 panel $A$ ) show that the hydrocarboncontaining fractions $\left(F_{1}\right.$ and $\left.F_{\mathrm{A}}\right)$ of both essential oils decreased IL$1 \beta$-induced NO production in a concentration-dependent manner, the highest concentrations achieving an inhibition of 55\% and $75 \%$, respectively, relative to cells treated with $\mathrm{IL}-1 \beta$ alone. The other three fractions of the essential oil of $L$. luisieri also showed some inhibitory activity which, nonetheless, did not exceed $35 \%$ relative to IL- $1 \beta$-treated cells. Fractions $F_{2.4}$ and $F_{2.5}$ of the essential oil of $E$. duriaei subsp. juresianum were only tested at a concentration of $10 \mu \mathrm{g} / \mathrm{ml}$, as higher concentrations were found to be cytotoxic (Supplementary data). These fractions, as well as fraction $F_{2.7}$ at

Table 1

Oligonucleotide primer pairs used for qRT-PCR.

\begin{tabular}{|c|c|c|c|}
\hline Gene name & Genbank accession number & Forward sequence & Reverse sequence \\
\hline iNOS & NM_000625.4 & 5'-AATCCAGATAA GTGACATAAG-3' & 5'-CTCCACATTGT TGTTGAT-3' \\
\hline MMP-1 & NM_001145938.1 & 5'-GAGTCTCCCAT TCTACTG-3' & 5'-TTATAGCATCA AAGGTTAGC-3' \\
\hline MMP-13 & NM_002422.3 & 5'-GTTTCCTATCTA CACCTACAC-3' & 5'-CTCGGAGACTGG TAATGG-3' \\
\hline TIMP-1 & NM_003254.2 & 5'-TGTTGCTGTGGC TGATAG-3' & 5'-CTGGTATAAGGT GGTCTGG-3' \\
\hline TIMP-3 & NM_000362.4 & $5^{\prime}$-CCATACACTATCCAC - $3^{\prime}$ & 5'-TAACAGCATTGAACA - $3^{\prime}$ \\
\hline Collagen II & NM_001844.4 & 5'-GGCAGAGGTA TAATGATAAGG-3' & 5'-ATTATGTCGTC GCAGAGG-3' \\
\hline Collagen I & NM_000088.3 & 5'GGAGGAGAGTCAGGA-3' & 5'-GCAACACAGTTACAC-3' \\
\hline Aggrecan & NM_001135 & 5'-CCTGGTGTGGCT GCTGTC-3' & 5'-CTGGCTCGGT GGTGAACTC-3' \\
\hline HPRT-1 & NM_000194.2 & 5'-TGACACTGGCA AAACAAT- $3^{\prime}$ & 5'-GGCTTATATCC AACACTTCG-3' \\
\hline
\end{tabular}


Table 2

Composition of the fractions of the essential oils of E. duriaei subsp juresianum and Lavandula luisieri.

\begin{tabular}{|c|c|c|c|c|c|}
\hline & Eryngium duriaei subsp juresianum & $\%$ & & Lavandula luisieri & $\%$ \\
\hline \multirow[t]{7}{*}{$F_{1}$} & E-caryophyllene & 29.5 & $F_{\mathrm{A}}$ & 3.5-dimethylene-1.4.4-trimethylcyclopentene & 10.4 \\
\hline & $\alpha$-neocallitropsene & 50.2 & & $\alpha$-pinene & 26.9 \\
\hline & Germacrene D & 2.7 & & $\beta$-pinene & 3.5 \\
\hline & $\beta$-selinene & 2.7 & & $\Delta$-3-carene & 5.2 \\
\hline & Bicyclogermacrene & 6.3 & & Limonene & 3.0 \\
\hline & Limonene & 0.1 & & $E$ - $\beta$-ocimene & 1.6 \\
\hline & Myrcene & $t$ & & Cyclosativene & 2.0 \\
\hline \multirow[t]{3}{*}{$F_{2.3}$} & Octanal & 9.3 & & $\alpha$-copaene & 2.2 \\
\hline & Caryophyllene oxide & 31.6 & & E-caryophyllene & 3.9 \\
\hline & Isocaryophyllene-14-al & 44.4 & & Alloaromadendrene & 1.2 \\
\hline \multirow[t]{4}{*}{$F_{2.4}$} & Unknown 1 & 22.8 & & $\beta$-selinene & 2.9 \\
\hline & Spathulenol & 9.8 & & $\alpha$-selinene & 3.5 \\
\hline & 14-hydroxy- $\beta$-caryophyllene & 38.0 & & $\delta$-cadinene & 6.7 \\
\hline & Unknown 2 & 6.6 & & Selina-3.7(11)-diene & 4.5 \\
\hline \multirow[t]{5}{*}{$F_{2.5}$} & Unknown 1 & 8.8 & $F_{\mathrm{B}}$ & trans- $\alpha$-necrodyl acetate & 30.5 \\
\hline & Spathulenol & 21.4 & & Lavandulyl acetate & 8.2 \\
\hline & 14-hydroxy- $\beta$-caryophyllene & 45.2 & & cis- $\alpha$-necrodyl acetate & 3.8 \\
\hline & Unknown 2 & 2.9 & & 1.8-cineole & 32.4 \\
\hline & Unknown 3 & 3.7 & & Lyratyl acetate & 2.4 \\
\hline \multirow[t]{20}{*}{$F_{2.7}$} & Caprylic acid & 8.1 & $F_{\mathrm{C}}$ & 1.10-di-epi-cubenol & 4.8 \\
\hline & Buthyhidroxytoluene (solvent contaminant) & 8.6 & & 2.3.4.4-tetramethyl-5-methylene-cyclopent-2-enone & 8.6 \\
\hline & Tetradecanoic acid & 40.5 & & Linalool & 11.9 \\
\hline & Hexadecanoic acid & 8.5 & & epi-cubenol & 1.3 \\
\hline & & & & trans- $\alpha$-necrodol & 20.1 \\
\hline & & & & Lavandulol & 2.2 \\
\hline & & & & Viridiflorol & 8.2 \\
\hline & & & & T-cadinol & 2.4 \\
\hline & & & & $T$-muurolol & 4.4 \\
\hline & & & & cis-linalool oxide (THP) & 3.2 \\
\hline & & & & Unkown $\left(\mathrm{C}_{10} \mathrm{H}_{16} \mathrm{O}\right)$ & 2.3 \\
\hline & & & & 1.1.2.3-tetramethyl-4-hidroxymethyl-2-ciclopentene & 7.2 \\
\hline & & & & 14-norcadin-5-ene-4-one (Isomer) & 4.3 \\
\hline & & & $F_{\mathrm{D}}$ & trans-linalool oxide (THF) & 12.6 \\
\hline & & & & $\alpha$-terpineol & 7.1 \\
\hline & & & & Verbenone & 2.5 \\
\hline & & & & $\alpha$-muurolol & 1.3 \\
\hline & & & & trans-verbenol & 3.1 \\
\hline & & & & Globulol & 2.5 \\
\hline & & & & $\alpha$-cadinol & 48.7 \\
\hline
\end{tabular}

A

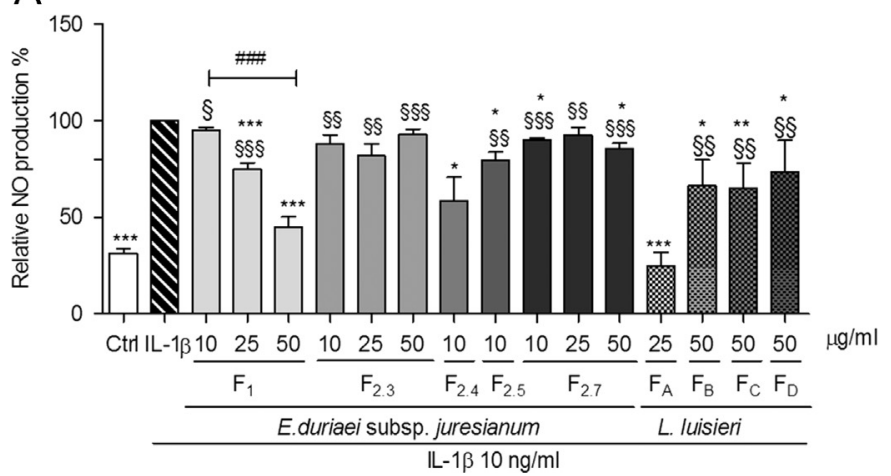

B

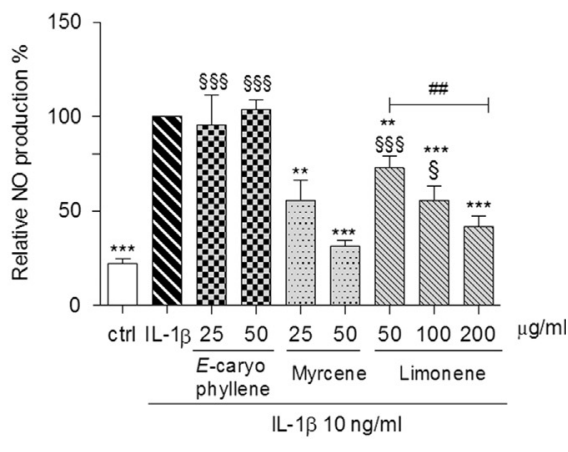

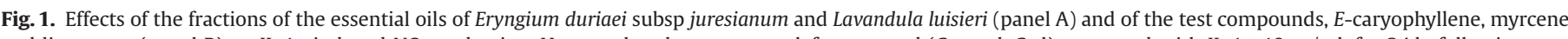

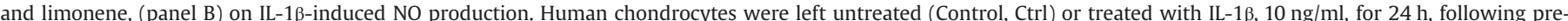

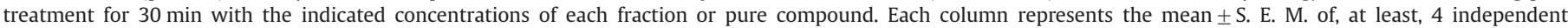

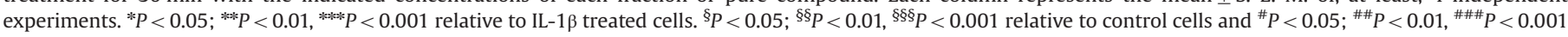
between the conditions indicated.

a concentration of $50 \mu \mathrm{g} / \mathrm{ml}$, also significantly inhibited IL-1 $\beta$-induced NO production, although to a lesser extent than found with $F_{1}$. No significant effects were obtained with $F_{2.3}$ at any of the concentrations tested. Therefore, the hydrocarbon-containing fractions $\left(F_{1}\right.$ and $\left.F_{\mathrm{A}}\right)$ of both essential oils were considered the most promising for selection of compounds for further studies.
As shown in Table 2, these fractions $\left(F_{\mathrm{A}}\right.$ and $\left.F_{1}\right)$ are composed of monoterpene and sesquiterpene hydrocarbons, mainly $\alpha$-pinene and 3,5-dimethylene-1,4,4-trimethylcyclopentene, and E-caryophyllene, $\alpha$-neocallitropsene, germacrene D, $\beta$-selinene and bicyclogermacrene, respectively. Of these compounds, only $\alpha$-pinene and $E$-caryophyllene are readily available from commercial sources 
and we have recently reported the differential activity of $\alpha$-pinene enantiomers as inhibitors of pro-inflammatory and catabolic pathways in human chondrocytes (Rufino et al., 2014b). Nonetheless, both essential oils have other minor components in common, namely the monoterpene hydrocarbons, myrcene and limonene, which were thus selected for pharmacological evaluation. Thus, high purity E-caryophyllene, myrcene and limonene (structural formulas are depicted in Fig. 2), obtained from commercial sources indicated in Section 2, were screened for their ability to inhibit IL-1 $\beta$-induced NO production.

The obtained results (Fig. 1 panel B) show that, at non-cytotoxic concentrations (Supplementary data), myrcene and limonene effectively inhibited IL- $1 \beta$-induced NO production, while E-caryophyllene had no significant effect at any of the concentrations tested.

Since myrcene and limonene showed inhibitory activity towards IL-1 $\beta$-induced NO production, various non-cytotoxic concentrations were then tested to determine the respective concentration required to inhibit NO production by $50 \%$ ( $\mathrm{IC}_{50}$ ) and thus, to compare their relative potencies. The $\mathrm{IC}_{50}$ values obtained are $37.3 \pm 1.1 \mu \mathrm{g} / \mathrm{ml}$ for myrcene and $85.3 \pm 1.2 \mu \mathrm{g} / \mathrm{ml}$ for limonene.

To determine whether the observed inhibition of NO production by myrcene and limonene is due to inhibition of iNOS expression, its mRNA (Fig. 3 panel B) and protein (Fig. 3 panel A) levels were evaluated. Treatment with myrcene, $50 \mu \mathrm{g} / \mathrm{ml}$, significantly diminished IL- $1 \beta$-induced iNOS mRNA and protein levels by $78 \%$ and $69 \%$, respectively, while inhibition by limonene, even at a concentration four fold higher, did not exceed $39 \%$ and $60 \%$, respectively.

\subsection{Inhibition of IL-1 $\beta$-induced NF- $\kappa B$ activation by myrcene and limonene}

To further elucidate the mechanisms by which the two compounds, myrcene and limonene, inhibit iNOS expression and to further evaluate their potential as anti-osteoarthritic drugs, their ability to inhibit IL-1 $\beta$-induced NF- $\kappa$ B activation was determined. $\mathrm{NF}-\kappa \mathrm{B}$ activation requires the phosphorylation, ubiquitination and proteasomal degradation of its natural inhibitor, NF- $\kappa B$ Inhibitor- $\alpha$ (I $\kappa \mathrm{B}-\alpha)$, which, in unstimulated cells, retains NF- $\kappa B$ dimers in the cytoplasm. Once I $\kappa \mathrm{B}-\alpha$ is degraded, the freed NF- $\kappa B$ dimers translocate to the nucleus and bind to specific sequences in the promoter region of target genes promoting their transcription (Hayden and Ghosh, 2008). Thus, we evaluated the protein levels of phosphorylated and total I $\mathrm{I} B-\alpha$ by western blot and the binding of the freed NF- $\kappa B$ dimers to a specific DNA sequence by ELISA.

Since human cartilage samples are scarce and a large number of cells is required, the ability of the test compounds to inhibit

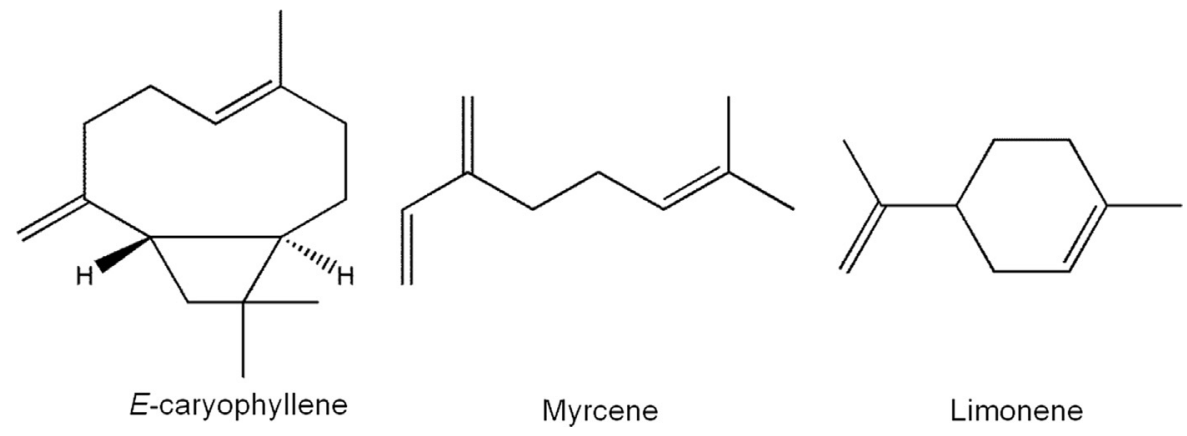

Fig. 2. Structural formulas of the pure compounds tested.

A

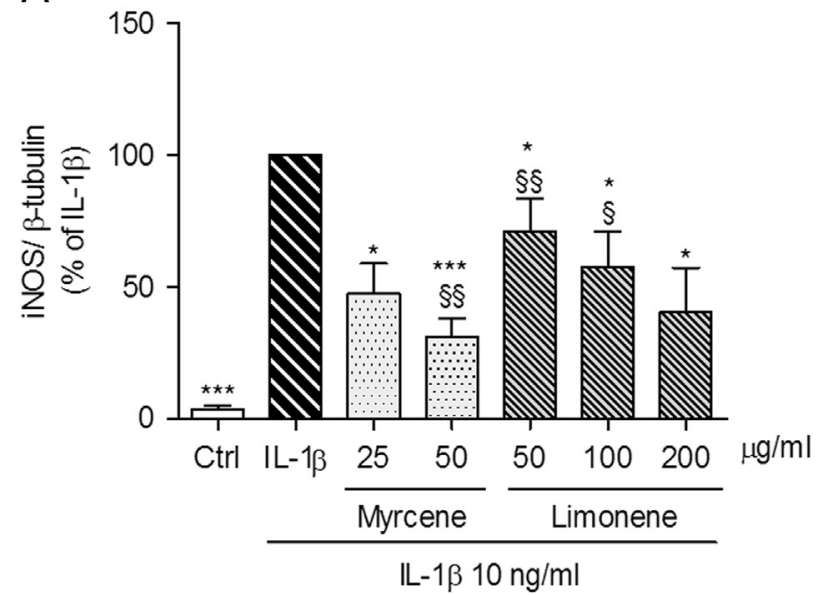

B

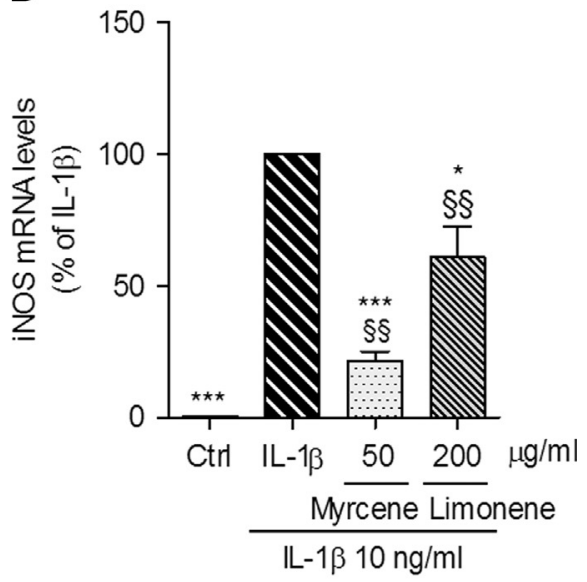

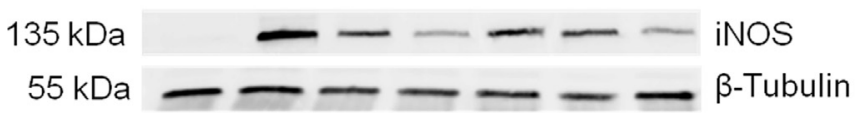

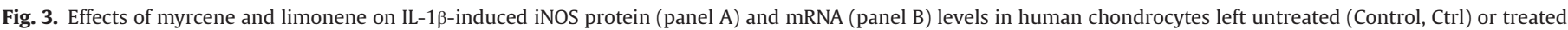

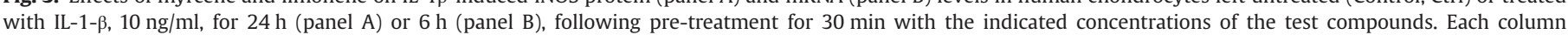

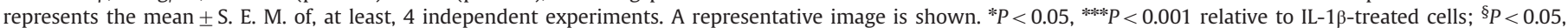
$\S \S P<0.01$ relative to control cells. 
A

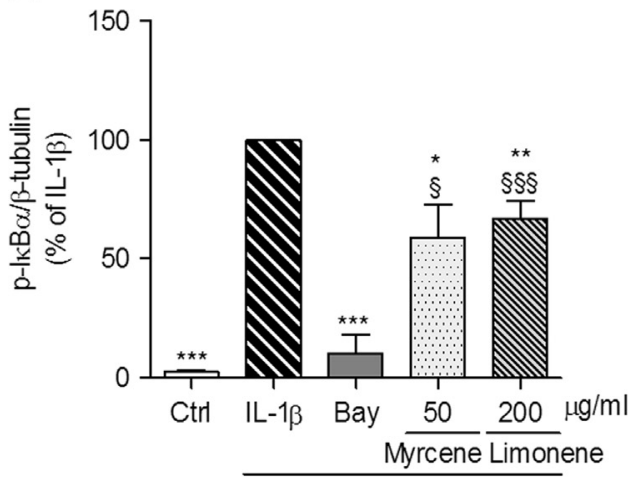

IL-1 $\beta, 10 \mathrm{ng} / \mathrm{ml}$

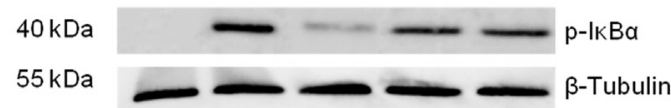

B

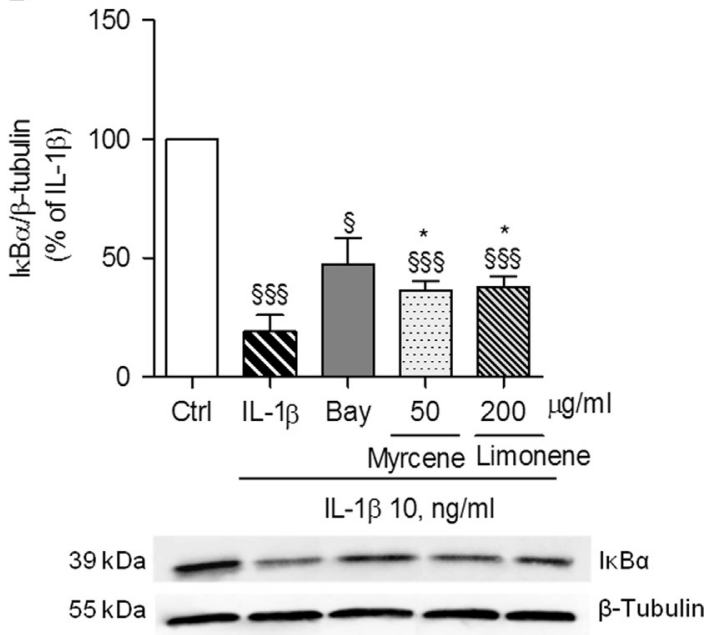

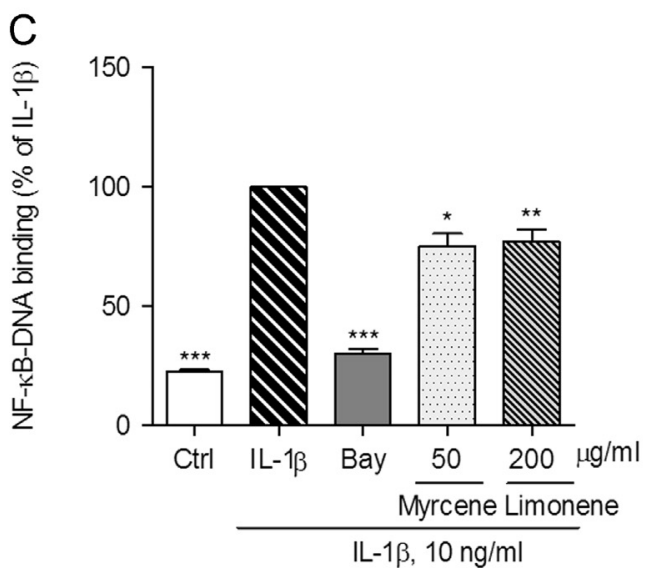

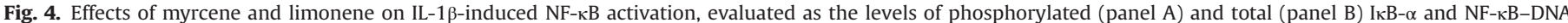

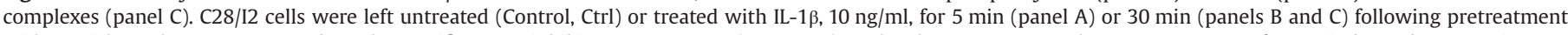

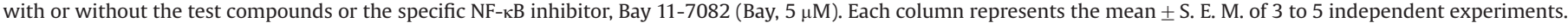
${ }^{*} P<0.05$, ${ }^{* *} P<0.01{ }^{* * *} P<0.001$ relative to IL-1 $\beta$-treated cells; ${ }^{\S} P<0.05,{ }^{\S \S \S} P<0.001$ relative to control cells.

IL-1 $\beta$-induced NF- $\kappa B-D N A$ binding was evaluated in the human chondrocytic cell line, C-28/I2, while the levels of phosphorylated and total I $\kappa \mathrm{B}-\alpha$ were evaluated in primary human chondrocytes. The results show that treatment with IL- $1 \beta$ dramatically increased

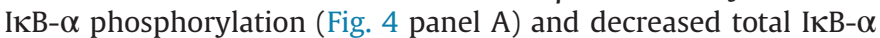
levels, reflecting its almost complete degradation (Fig. 4 panel B), followed by increased NF- $\mathrm{KB}-\mathrm{DNA}$ binding (Fig. 4 panel C). Treatment with Bay 11-7082 (Bay), a specific NF- $\kappa$ B inhibitor that selectively prevents IKB- $\alpha$ phosphorylation, or with the test compounds markedly reduced IL- $1 \beta$-induced I $\kappa \mathrm{B}-\alpha$ phosphorylation (Fig. 4 panel A) and degradation (Fig. 4 panel B), as well as NF$\kappa \mathrm{B}$-DNA binding (Fig. 4 panel $\mathrm{C}$ ). Interestingly, although the

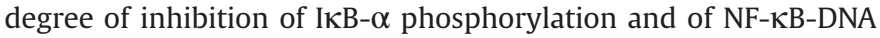
binding achieved with Bay was significantly higher than that obtained with myrcene and limonene, IкB- $\alpha$ degradation was similarly decreased by the three compounds.

\subsection{Effects of myrcene and limonene on IL-1 $\beta$-induced MAPK activation}

Together with NF- $\kappa \mathrm{B}$ activation, signaling pathways involving activation of members of the MAPK family also play an important role in the proteolytic cartilage degradation process, namely in the expression of MMPs (Mengshol et al., 2000). Thus, the ability of myrcene and limonene to inhibit IL- $1 \beta$-induced MAPK activation was assessed by evaluating their phosphorylation levels.
Myrcene and limonene showed quite distinct effects on IL-1 $\beta$ induced JNK (Fig. 5 panel A), p38 (Fig. 5 panel B) and ERK1/2 (Fig. 5 panel C) phosphorylation. Myrcene significantly reduced IL-1 $\beta$ induced phosphorylation of the three MAPKs, while limonene was effective in reducing p38 phosphorylation by near $39 \%$, but increased phosphorylated ERK $1 / 2$ by $30 \%$ and had no significant effect on JNK.

\subsection{Modulation of inflammatory, catabolic, anti-catabolic and extracellular matrix gene expression by myrcene and limonene}

Then, we evaluated the ability of the compounds tested to counteract the effects of IL- $1 \beta$ on the expression of catabolic, anticatabolic and extracellular matrix genes, which, at least in part, are mediated by NF- $\kappa \mathrm{B}$ and the MAPKs (Goldring and Otero, 2011). As expected, treatment of human chondrocytes with IL-1 $\beta(10 \mathrm{ng} / \mathrm{ml})$ increased MMP-1 and -13 mRNA levels by nearly 9- and 5-fold, respectively (Fig. 6 panel A), while decreasing TIMP-1 and -3 expressions (Fig. 6 panel B). Myrcene decreased the mRNA levels of both MMPs by nearly $60 \%$, relative to IL-1 $\beta$, while limonene reduced MMP-1 and -13 levels by $51 \%$ and $39 \%$, respectively. Nevertheless, the reduction of MMP-13 levels elicited by limonene did not reach statistical significance.

On the other hand, limonene did not significantly change the inhibitory effect of IL- $1 \beta$ on TIMP- 1 and -3 mRNA levels, even though it showed a tendency to increase TIMP-1 levels that did not 
A

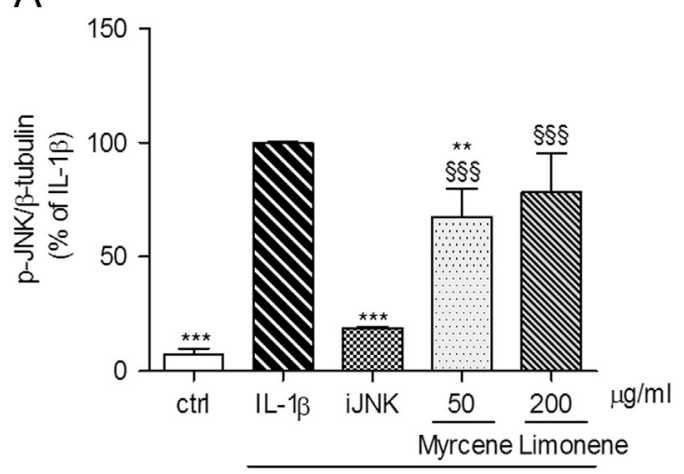

$-1 \beta, 10 \mathrm{ng} / \mathrm{ml}$

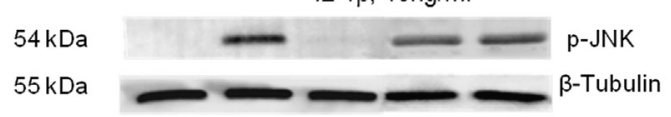

B

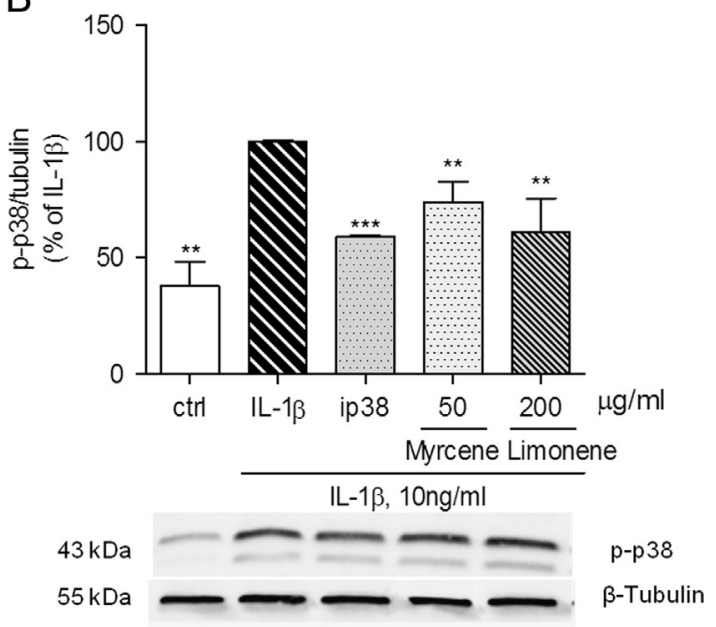

\section{C}

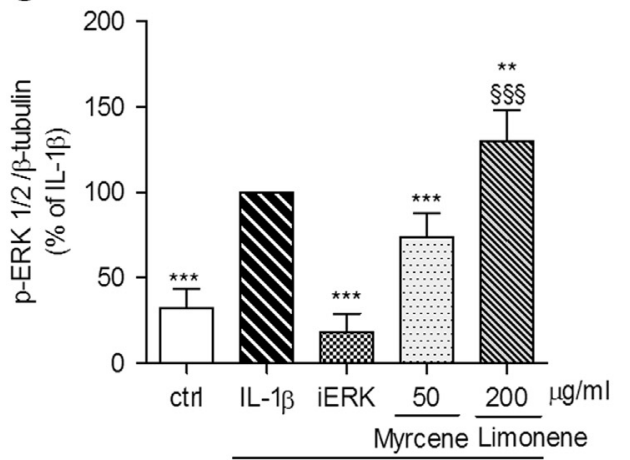

LL-1 $\beta, 10 \mathrm{ng} / \mathrm{ml}$

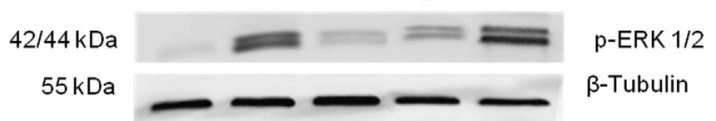

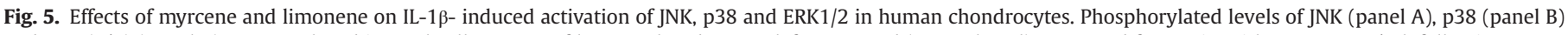

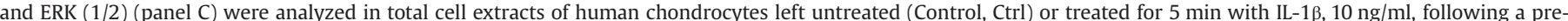

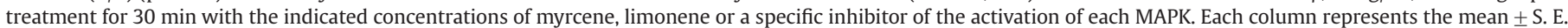

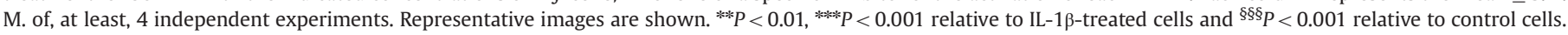
iJNK: JNK inhibitor, SP600125 (20 $\mu \mathrm{M})$; ip38: p38 inhibitor, SB203580 (20 $\mu \mathrm{M})$; iERK: ERK1/2 inhibitor, U0126 (10 $\mu \mathrm{M})$.

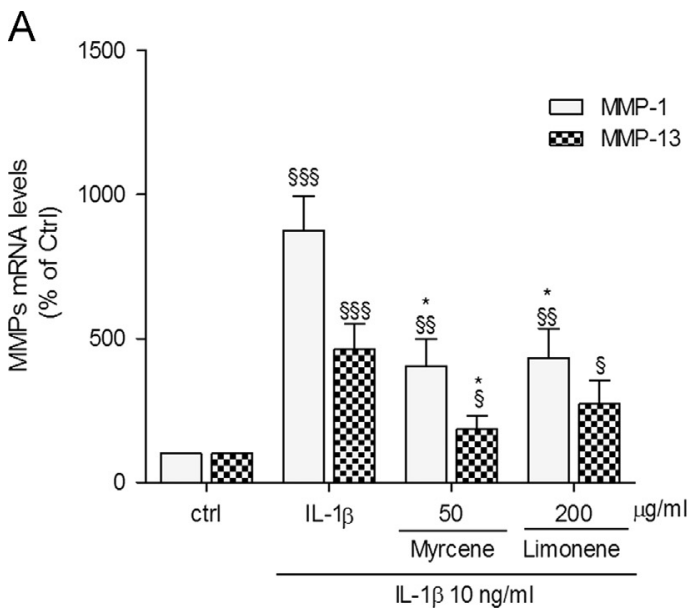

B

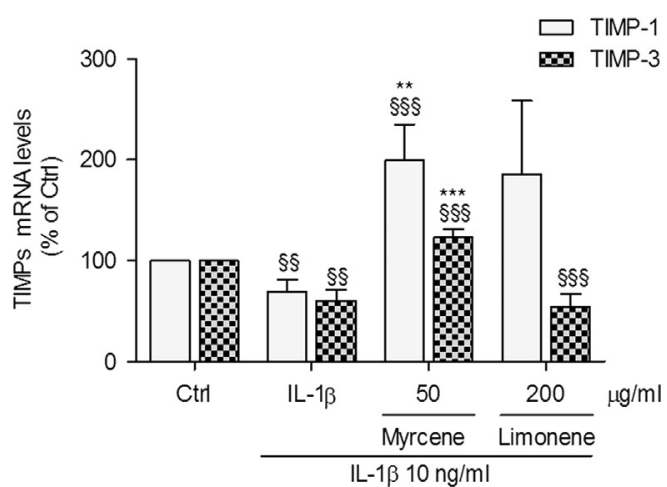

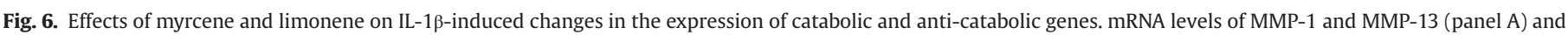

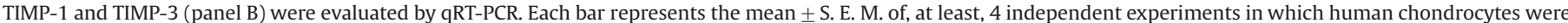

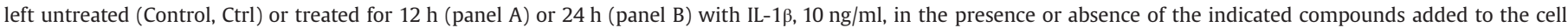
cultures $30 \mathrm{~min}$ before IL-1 $\beta .{ }^{*} P<0.05$, ${ }^{* *} P<0.01$, ${ }^{* * *} P<0.001$ relative to IL-1 $\beta$-treated cells and ${ }^{\S} P<0.05$, ${ }^{\S \S} P<0.01$, ${ }^{\S \S} P<0.001$ relative to control cells. 
A

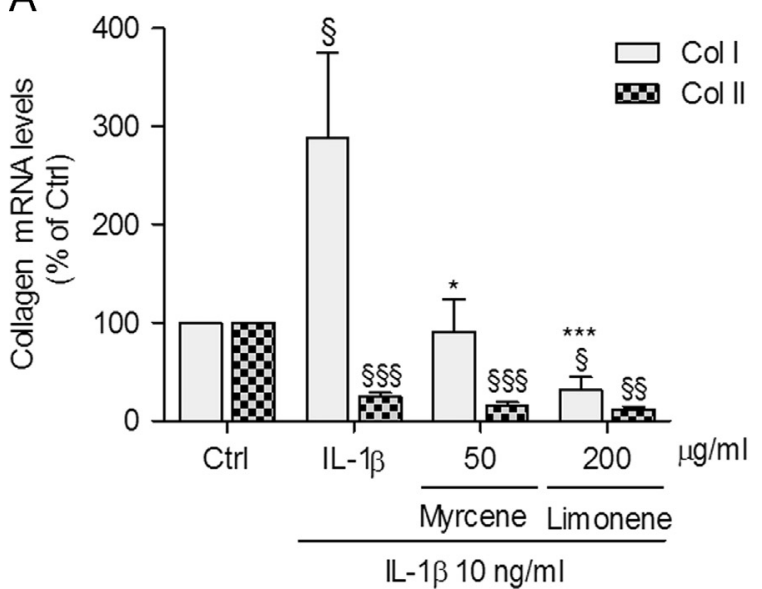

B

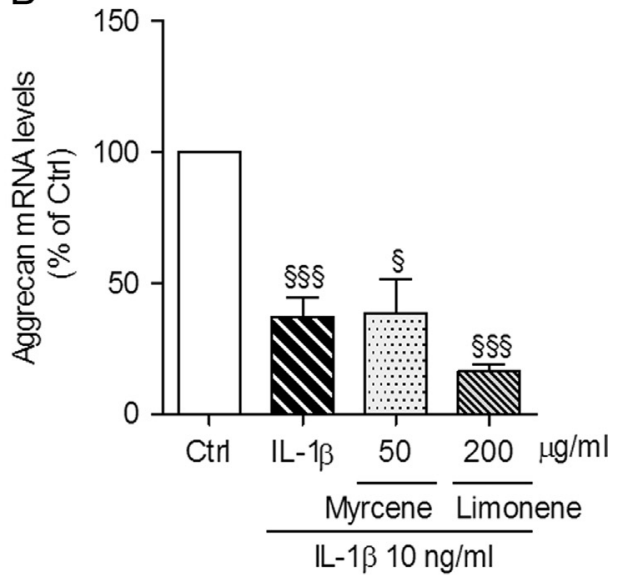

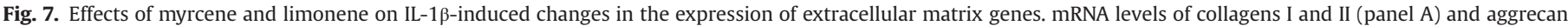

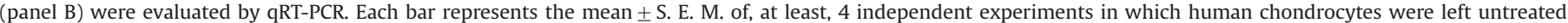

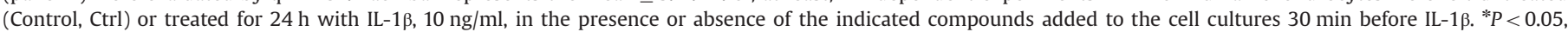
${ }^{* * * *} P<0.001$ relative to IL- $1 \beta$-treated cells and ${ }^{\S \S} P<0.01$, ${ }^{\S \S} \mathrm{P}<0.001$ relative to control cells.

reach statistical significance. On the contrary, myrcene not only completely reversed the inhibitory effect exerted by IL-1 $\beta$, as it effectively increased TIMP-1 and -3 levels approximately 2- and 1.3-fold above those in untreated control cells, respectively, which correspond to even larger increases if compared to TIMP-1 and -3 mRNA levels in cells treated with IL- $1 \beta$ alone.

To assess the potential ability of the test compounds to inhibit the deleterious effects of IL- $1 \beta$ in anabolic responses that are essential for repair of damaged articular cartilage, the expression of collagen II and aggrecan was evaluated. Furthermore, the ability of the test compounds to decrease the expression of the non-cartilage specific, collagen I gene, induced by IL-1 $\beta$, was also evaluated. Chondrocyte treatment with $10 \mathrm{ng} / \mathrm{ml} \mathrm{IL-1 \beta}$, for $24 \mathrm{~h}$, significantly increased collagen I mRNA levels, while decreasing those of collagen II and aggrecan, relative to untreated control cells (Fig. 7). Treatment of human chondrocytes with myrcene or limonene caused no significant changes on collagen II (Fig. 7 panel A) and aggrecan (Fig. 7 panel B) mRNA levels compared to those in cells treated with IL-1 $\beta$ alone. Nonetheless, both treatments were able to completely abolish or even reverse the increase in collagen I mRNA levels induced by IL-1 $\beta$.

\section{Discussion}

The results obtained in this study identify two monoterpene hydrocarbons, myrcene and limonene, as capable of inhibiting IL-1 $\beta$ induced NO production in human chondrocytes. The specific activities (activity $/ \mu \mathrm{g}$ ) relative to inhibition of IL-1-induced NO production, of myrcene and limonene are $1.33 \% / \mu \mathrm{g}$ and $0.57 \% / \mu \mathrm{g}$, respectively, while for the active fractions $\left(F_{1}\right.$ and $\left.F_{\mathrm{A}}\right)$ of the essential oils of $E$. duriaei subsp. juresianum and L. luisieri they are $1 \% / \mu \mathrm{g}$ and $3.0 \% / \mu \mathrm{g}$, respectively. Since myrcene and limonene are only minor components of those fractions, it is likely that other constituents are also active and contribute to the effects observed. Moreover, since both fractions contain several distinct compounds, none of which is present in sufficiently high amounts to justify the effects observed, either the active compound in those fractions is significantly more potent than myrcene and limonene or various active compounds, including these two, act synergistically, or at least, additively, to achieve a similar or even higher degree of inhibition of IL-1-induced NO production. Unfortunately, as mentioned in Section 3.1, the major components of those fractions are either not readily available from commercial sources or have been previously studied, as is the case for $(+)-\alpha-$ pinene that we showed to have anti-inflammatory and anti-catabolic activities in human chondrocytes (Rufino et al., 2014b). Thus, identification of the other active compounds in those fractions is, at present, impracticable.

On the other hand, the sesquiterpene hydrocarbon, E-caryophyllene, which is a major component of the active fraction of the essential oil of $E$. duriaei subsp. juresianum, is completely inactive. This finding is somewhat unexpected as E-caryophyllene has been reported to exert anti-inflammatory effects by activating cannabinoid CB2 receptors (Bento et al., 2011; Medeiros et al., 2007) and endogenous and synthetic cannabinoids have been reported to decrease inflammation in animal models of arthritis (Sumariwalla et al., 2004) and to inhibit IL-1-induced NO production in bovine chondrocytes (Mbvundula et al., 2005).

The two active compounds, myrcene and limonene, show clear qualitative and quantitative differences in terms of ability to inhibit IL-1 $\beta$-induced responses. Myrcene was the most potent in inhibiting NO production, as indicated by an $\mathrm{IC}_{50}$ value less than half of that found for limonene. Myrcene was also more effective than limonene in preventing other inflammatory and catabolic responses in human chondrocytes, namely expression of iNOS, MMP-1 and MMP-13 induced by IL-1 $\beta$, likely reflecting, at least in part, the stronger inhibition of NF- $\kappa B$ and the ability to inhibit all three MAPKs. These findings are in agreement with another study that reported anti-inflammatory properties of myrcene in a mouse model of pleurisy induced by zymosan and bacterial lipopolysaccharide where it inhibited the production of NO and inflammatory cytokines (Souza et al., 2003). Furthermore, myrcene, but not limonene, caused a net increase in the expression of the anticatabolic genes, TIMP-1 and -3 , which in combination with the decrease in MMP-1 and -13 expression can cause a significant reduction of the catabolic milieu characteristic of OA.

On the other hand, myrcene also completely prevented the increase in collagen I induced by IL-1 $\beta$. Collagen I is not normally found in articular cartilage and its expression increases in $\mathrm{OA}$ and in association with chondrocyte dedifferentiation, a process that involves several alterations of chondrocyte gene expression and morphology and leads to the formation of fibrocartilage (Martin et al., 2001). Therefore, even though it did not increase the specific anabolic responses of human chondrocytes, myrcene may be effective in preventing chondrocyte dedifferentiation associated with increased collagen I expression, while decreasing inflammatory and catabolic processes directly involved in cartilage destruction.

Reports on pharmacological properties of limonene are scarce, but it has been shown to have antimicrobial properties (Bevilacqua et al., 
2010) and anti-inflammatory effects in a mouse model of LPS-induced acute lung injury by suppressing MAPK and NF- $\kappa B$ pathways (Chi et al., 2012). The results presented here only partially agree with this study, since limonene inhibited NF- $\mathrm{KB}$ and $\mathrm{p} 38$ activation, but did not affect IL-1 $\beta$-induced JNK and actually potentiated ERK1/2 activation, suggesting that this compound has cell- and/or stimulus-specific effects. On the other hand, ERK1/2 is required for a number of cellular processes, including activation of $c$-fos expression which, among other functions, is involved in cell survival (Karin et al., 1997; Shaulian and Karin, 2002). Whether increased activation of ERK1/2 by limonene contributes to enhance chondrocyte survival was not addressed in this study, but is an interesting possibility to study further, as increased chondrocyte death is a relevant feature of OA (Johnson et al., 2008). Nonetheless, since ERK1/2 has also been shown to inhibit proteoglycan synthesis and to promote inflammatory and catabolic responses in chondrocytes (Scherle et al., 1997), the net effect resulting from its induction by limonene is likely undesirable, compromising its potential utility as a therapeutic agent in OA.

Form another point of view, it is intriguing that limonene induced ERK1/2 activation while decreasing p38 and not affecting JNK activation. This is even more puzzling as myrcene was able to inhibit the activation of all three MAPKs. Even though we cannot provide an explanation for the differential effects of both compounds, it seems reasonable to admit that they may act on distinct molecular targets. Although the exact signaling pathways that link IL-1 $\beta$ binding to its receptor to downstream events are still incompletely understood, the immediate upstream activators of each MAPK have been identified. While some of those, namely the mitogen-activated protein kinase kinase 4 (MKK4 or MEK4), can activate both JNK and p38, others specifically activate each of these MAPK. MKK3 and MKK6 are p38 activators while MKK7 activates JNK and MKK1 activates ERK1/2 (Weber et al., 2010). Thus, limonene may inhibit MKK3 or MKK6 without affecting MKK4 or MKK7 or any other upstream intermediate, while inducing MKK1 activation, either direct or indirectly. On the other hand, myrcene may act on another intermediate common to the three MAPK and also to NF- $\kappa B$ or instead it may independently inhibit the MAPK and $\mathrm{NF}-\kappa \mathrm{B}$ signaling pathways. Clearly, further studies are required to identify the specific molecular targets of myrcene and limonene. Nonetheless, this may be a difficult task given the complexity of each of these pathways and the extensive cross-talk between them (Virtue et al., 2012; Weber et al., 2010).

In comparison with $(+)-\alpha$-pinene that we previously reported to have anti-inflammatory and anti-catabolic properties in human chondrocytes (Rufino et al., 2014b), myrcene shows potential advantages since, besides inhibiting iNOS expression and activity and NF- $\mathrm{\kappa B}$ and JNK activation to a similar extent but at lower concentrations, it further decreased ERK1/2 and p38 activation and increased anticatabolic responses, namely TIMP-1 and -3 expression. Moreover, myrcene can also promote the maintenance of the differentiated chondrocyte phenotype, as it also decreased collagen I expression. Nonetheless, none of the compounds tested, nor $(+)-\alpha$-pinene, seem effective in promoting the expression of articular cartilage matrixspecific genes and, thus, are unlike to promote the repair of areas already damaged. Moreover, the potency of myrcene is relatively low which may also hinder its therapeutic efficacy.

\section{Conclusions}

Myrcene has significant anti-inflammatory and anti-catabolic properties in vitro suggesting that it may be useful to halt or, at least, slow down cartilage destruction and, thus, OA progression. Future studies in in vivo models of $\mathrm{OA}$ are thus warranted to evaluate its potential as a disease-modifying osteoarthritis drug.

\section{Acknowledgment}

This work was co-funded by FEDER (QREN), through Programa Mais Centro under project CENTRO-07-ST24-FEDER-002006, and through Programa Operacional Factores de Competitividade - COMPETE and national funds via FCT - Fundação Portuguesa para a Ciência e a Tecnologia under projects PestC/SAU/LA0001/20132014, Pest-OE/SAU/ UI0177/2011, PTDC/EME-TME/113039/2009, and the PhD fellowships, SFRH/BD/47470/2008, SFRH/BD/78188/2011 and SFRH/BD/79600/2011.

\section{Appendix A. Supporting information}

Supplementary data associated with this article can be found in the online version at http://dx.doi.org/10.1016/j.ejphar.2015.01.018.

\section{References}

Adams, R.P., 1995. Identification of Essential Oil Components by Gas Chromatography/Quadrupole Mass Spectroscopy. Allured Publishing Corporation, Carol Stream, Illinois, USA.

Bento, A.F Marcon, R, Dutra, R.C. Claudino, R.F Cola, M., Leite, D.F, Calixto, JB. 2011. $\beta$-Caryophyllene inhibits dextran sulfate sodium-induced colitis in mice through CB2 receptor activation and PPARgamma pathway. Am. J. Pathol. 178, 1153-1166.

Berenbaum, F., 2004. Signaling transduction: target in osteoarthritis. Curr. Opin. Rheumatol. 16, 616-622.

Bevilacqua, A., Corbo, M.R., Sinigaglia, M., 2010. In vitro evaluation of the antimicrobial activity of eugenol, limonene, and citrus extract against bacteria and yeasts, representative of the spoiling microflora of fruit juices. J. Food Prot. 73, 888-894.

Boileau, C., Martel-Pelletier, J., Moldovan, F., Jouzeau, J.Y., Netter, P., Manning, P.T., Pelletier, J.P., 2002. The in situ up-regulation of chondrocyte interleukin-1converting enzyme and interleukin-18 levels in experimental osteoarthritis is mediated by nitric oxide. Arthritis Rheumatol. 46, 2637-2647.

Calixto, J.B., Campos, M.M., Otuki, M.F., Santos, A.R., 2004. Anti-inflammatory compounds of plant origin. Part II. Modulation of pro-inflammatory cytokines, chemokines and adhesion molecules. Planta Med. 70, 93-103.

Cavaleiro, C., Goncalves, M.J., Serra, D., Santoro, G., Tomi, F., Bighelli, A., Salgueiro, L., Casanova, J., 2011. Composition of a volatile extract of Eryngium duriaei subsp. juresianum (M. Lainz) M. Lainz, signalised by the antifungal activity. J. Pharm. Biomed. Anal. 54, 619-622.

Chi, G., Wei, M., Xie, X., Soromou, L.W., Liu, F, Zhao, S., 2012. Suppression of MAPK and NF-kappaB pathways by limonene contributes to attenuation of lipopolysaccharide-induced inflammatory responses in acute lung injury. Inflammation 36, 501-511.

Goldring, M.B., Goldring, S.R., 2007. Osteoarthritis. J. Cell. Physiol. 213, 626-634.

Goldring, M.B., Otero, M., 2011. Inflammation in osteoarthritis. Curr. Opin. Rheumatol. 23, 471-478.

Goldring, M.B., Otero, M., Tsuchimochi, K., Ijiri, K., Li, Y., 2008. Defining the roles of inflammatory and anabolic cytokines in cartilage metabolism. Ann. Rheum. Dis. 67 (Suppl. 3), Siii75-Siiir2.

Green, L.C., Wagner, D.A., Glogowski, J., Skipper, P.L., Wishnok, J.S., Tannenbaum, S.R., 1982. Analysis of nitrate, nitrite, and $\left[{ }^{15} \mathrm{~N}\right]$ nitrate in biological fluids. Anal. Biochem. 126, 131-138.

Hayden, M.S., Ghosh, S., 2008. Shared principles in NF-kappaB signaling. Cell 132, 344-362.

Johnson, E.O., Charchandi, A., Babis, G.C., Soucacos, P.N., 2008. Apoptosis in osteoarthritis: morphology, mechanisms, and potential means for therapeutic intervention. J. Surg. Orthop. Adv. 17, 147-152.

Joulain, D., 1998. The Atlas of Spectral Data of Sesquiterpene Hydrocarbons. Hamburg Verlag, Hamburg.

Kaplan, W., Wirtz, V.J., Mantel-Teeuwisse, A., Stolk, P., Duthey, B., Laing, R., 2013. Priority Medicines for Europe and the World-2013 Update. WHO Library Cataloguing-in-Publication Data.

Karin, M., Liu, Z., Zandi, E., 1997. AP-1 function and regulation. Curr. Opin. Cell Biol. 9, 240-246.

Khalife, S., Zafarullah, M., 2011. Molecular targets of natural health products in arthritis. Arthritis Res. Ther. 13, 102.

Martin, I., Jakob, M., Schafer, D., Dick, W., Spagnoli, G., Heberer, M., 2001. Quantitative analysis of gene expression in human articular cartilage from normal and osteoarthritic joints. Osteoarthr. Cartil. 9, 112-118.

Mbvundula, E.C., Bunning, R.A., Rainsford, K.D., 2005. Effects of cannabinoids on nitric oxide production by chondrocytes and proteoglycan degradation in cartilage. Biochem. Pharmacol. 69, 635-640.

McLafferty, W., 2009. Wiley Registry of Mass Spectral Data 9th/NIST 08. Mass Spectral Library.

Medeiros, R., Passos, G.F., Vitor, C.E., Koepp, J., Mazzuco, T.L., Pianowski, L.F., Campos, M.M., Calixto, J.B., 2007. Effect of two active compounds obtained 
from the essential oil of Cordia verbenacea on the acute inflammatory responses elicited by LPS in the rat paw. Br. J. Pharmacol. 151, 618-627.

Mengshol, J.A., Vincenti, M.P., Coon, C.I., Barchowsky, A., Brinckerhoff, C.E., 2000. Interleukin-1 induction of collagenase 3 (matrix metalloproteinase 13) gene expression in chondrocytes requires p38, c-Jun N-terminal kinase, and nuclear factor kappaB: differential regulation of collagenase 1 and collagenase 3 . Arthritis Rheumatol. 43, 801-811.

Miguel, M.G., 2010. Antioxidant and anti-inflammatory activities of essential oils: a short review. Molecules 15, 9252-9287.

Neves, A., Rosa, S., Goncalves, J., Rufino, A., Judas, F., Salgueiro, L., Lopes, M.C. Cavaleiro, C., Mendes, A.F., 2009. Screening of five essential oils for identification of potential inhibitors of IL-1-induced NF-kappaB activation and NO production in human chondrocytes: characterization of the inhibitory activity of alpha-pinene. Planta Med. 76, 303-308.

Nolan, T., Hands, R.E., Bustin, S.A., 2006. Quantification of mRNA using real-time RT-PCR. Nat. Protoc. 1, 1559-1582.

Rosa, S.C., Judas, F., Lopes, M.C., Mendes, A.F., 2008. Nitric oxide synthase isoforms and NF-kappaB activity in normal and osteoarthritic human chondrocytes: regulation by inducible nitric oxide. Nitric Oxide 19, 276-283.

Rufino, A.T. Ferreira, IV., Judas, F, Salgueiro, L, Lopes, M.C. Cavaleiro, C. Mendes, A.F. 2014a. Differential effects of Lavandula luisieri and Eryngium duriaei subsp. juresianum essential oils in cell models of two chronic inflammatory diseases. Pharm. Biol., http://dx.doi.org/10.3109/13880209.2014.970701.

Rufino, A.T., Ribeiro, M., Judas, F., Salgueiro, L., Lopes, M.C., Cavaleiro, C., Mendes, A.F., 2014b. Anti-inflammatory and chondroprotective activity of (+)-alpha-pinene: structural and enantiomeric selectivity. J. Nat. Prod. 77, 264-269.

Sasaki, K., Hattori, T., Fujisawa, T., Takahashi, K., Inoue, H., Takigawa, M., 1998. Nitric oxide mediates interleukin-1-induced gene expression of matrix metalloproteinases and basic fibroblast growth factor in cultured rabbit articular chondrocytes. J. Biochem. 123, 431-439.

Scherle, P.A., Pratta, M.A., Feeser, W.S., Tancula, E.J., Arner, E.C., 1997. The effects of IL-1 on mitogen-activated protein kinases in rabbit articular chondrocytes. Biochem. Biophys. Res. Commun. 230, 573-577.

Shaulian, E., Karin, M., 2002. AP-1 as a regulator of cell life and death. Nat. Cell Biol. 4, E131-E136.

Souza, M.C., Siani, A.C., Ramos, M.F. Menezes-de-Lima, O.J., Henriques, M.G., 2003. Evaluation of anti-inflammatory activity of essential oils from two Asteraceae species. Pharmazie 58, 582-586.

Sumariwalla, P.F., Gallily, R., Tchilibon, S., Fride, E., Mechoulam, R., Feldmann, M., 2004. A novel synthetic, nonpsychoactive cannabinoid acid (HU-320) with antiinflammatory properties in murine collagen-induced arthritis. Arthritis Rheumatol. 50, 985-998.

Troeberg, L., Nagase, H., 2012. Proteases involved in cartilage matrix degradation in osteoarthritis. Biochim. Biophys. Acta 1824, 133-145.

Videira, R., Castanheira, P., Grãos, M., Salgueiro, L., Faro, C., Cavaleiro, C., 2013. A necrodane monoterpenoid from Lavandula luisieri essential oil as a cellpermeable inhibitor of BACE-1, the $\beta$-secretase in Alzheimer's disease. Flavour Fragr. J. 28, 380-388.

Virtue, A., Wang, H., Yang, X.F., 2012. MicroRNAs and toll-like receptor/interleukin-1 receptor signaling. J. Hematol. Oncol. 5, 66 .

Weber, A., Wasiliew, P., Kracht, M., 2010. Interleukin-1 (IL-1) pathway. Sci. Signal. 3, $\mathrm{cm} 1$.

Zhang, Y., Jordan, J.M., 2010. Epidemiology of osteoarthritis. Clin. Geriatr. Med. 26 355-369. 